\section{ANALYSING SHAPES}

\section{Morphanalysis}

By Graham Rabey. Pp. viii + 232. (Graham Rabey: London, 1968. Available from H. K. Lewis, London.) n.p.

Miost biologists are concerned with form and the majority, not content with descriptive morphology alone, strive to analyse, compare and measure forms which in life are continually changing. These aims are often thwarted, however, by just this change in relative spatial relationships that all parts of a growing or changing structure undergo. In this book the author submits a synopsis of his solution to this problem. After a historical review of previous artistic and soientific approaches to the analysis of plane and solid figures he reaches the conclusion that the use of a rectangular coordinate system provides the most satisfactory method for fixing shapes in space. He also points out and later enlarges on the fact that coordinates, once established, provide suitable data for application to other mathematical methods.

The real problem "that every thing moves" is now introduced and the author rightly states that the system used for orientation on the coordinates must allow complete freedom of transformation of the rorm while retaining a constant relationship to these. This is achieved by placing two arbitrarily chosen features on the $y$ axis with the mid-point between them lyirg at the intersection of $x, y$ and $z$ axes. In the solid case the form is rotated until a third feature lies on a plane to vhich it remains constrained. This method of reference and orientation is the main contribution that this book makes and is the basis of "morphanalysis". The subseciuent description of the equipment used illustrates the ingenuity that the author has shown in the application of this method to the human head and many of these ideas could be adapted to suit other situations.

One wonders whether the author has been right to publish an abridged version of his complete work in this way. The text is unattractive and the presentation has the form of a primer - repetitive and naive, but at the same time pedagogic. Whether the aim of the method is completely achieved is also questionable. It certainly provides a tidy method for analysing a single form or arranging a series of related forms, but although, as is stressed, the fixed reference point has no biological significance, it still remains dependent on two that have, with the result that an interpretation of asymmetric growth or distortion might become more rather than less difficult to make. A useful contribution is made in this book which may stimulate some workers to accept Rabey's invitation to investigate the use of "morphanalysis" in their own field.

E. C. B. Hall-CragGs

\section{CARCINOGENIC ACTIVITY}

\section{Chemical Induction of Cancer}

Structural Bases and Biological Mechanisms. Vol. 1. By Joseph C. Arcos, Mary F. Argus and George Wolf. Pp. xxiii +491 . (Academic Press: Now York and London, August 1968.) 224s.

THIs is the first instalment of a three-volume second edition of George Wolf's 1952 monograph published under the same title. The present volume is concerned firstly with the fundamental aspects of organic chemistry, molecular structure and bonding, and secondly with the nature of tumours and methods of testing for carcinogenic activity. The authors' intention is that it should be of benefit to physicians, biologists, pathologists, biochemists, synthetic organic chemists and physicists. A priori, such an intention seems ambitious and perusal of the introduction does little to allay one's doubts. Here the style is turgid without achieving clarity or accuracy. Sentences such as "Growth is controlled, and differentiation takes place, through the action of yet scantily known forces or properties within each cell, probably connected with the functions of the hereditary substance of the chromosomes" follow one after another without the relief of a single, simple, unqualified statement. Fortunately, the rest of the book suffers little from the same fault.

In so far as I manage to pass as a pathologist, I am, theoretically, among those who stand to benefit from reading this series. In practice, I drew back from reading all of the 282 pages of the first section devoted to fundamental aspects of organic chemistry, not that such knowledge outside my own discipline would not do me good, but life is short and I already know where to go for this kind of honey when I need it. Wherever I dipped, however, the text seemed easy to follow and entirely lacking in the turgidity of the introduction. Valence, resonance and secondary valence forces are considered at length, and, according to Professor A. B. Foster, whom I consulted, "aceurately".

The section on the nature of tumours is easy to read and orthodox in content. Some of the 17 plates intended to illustrate the pathology of induced tumours are excellent, but others (pages 320,326, 331, 335 and 336) are poor or indifferent in quality.

Few would accept, without reservation, that "the only truly valid criterion of the carcinogenic activity or absence of activity of a chemical substance is whether or not it produces tumours in animal assays" (page 340). It is well known that animals may be "primed" naturally in relation to the induction of cancer, so that a seemingly nonspecific stimulus may result in the appearance of cancers. Thus malignant lymphoma may follow adrenalectomy in mice carrying the Gross leukaemia virus. The need for post-mortem examination to be carried out by experienced biologists or pathologists is rightly stressed, but the "general purpose autopsy record form" illustrated on page 411 does not provide enough room for the description of macroscopic appearance at necropsy.

The book is unusual in the subjects it attempts to combine. Whether it was wise to try to combine them will only be clear when volumes two and three become available. It is possible that a uniquely valuable synthesis has been achieved. If not, the net gain may be simply the availability of yet three more books on the all-inclusive subject of cancer.

F. J. C. RoE

\section{EPIGENIC PROCESSES}

\section{Geochemistry of Epigenesis}

By Aleksandr I. Perel'man. Translated from the Russian by N. N. Kohanowski. (Monographs in Geoscience.) Pp. xiii +266 . (Plenum Press: New York, 1967.) n.p.

Epigenesis, as Perel'man understands it, embraces all those geophysical and geochemical processes of addition, subtraction and modification that originate under conditions of low temperature near the surface of the Earth, that is, in the supergene zone.

Such processes are responsible for those modifications of the landscape that are affected by accumulations of rock debris or the sculpturing effects of erosion. They are also responsible for the development of soils and the consolidation of sediments, for certain types of rock alteration and for the genesis of some stratabound ore deposits. In addition, these processes have ensured that commonly associated with sub-outcropping ore deposits are dispersions of the ore elements in the neighbouring soils, vegetation, and river systems. As such phenomena facilitate the search for ore by geochemical methods, the factors determining their character are of the utmost 